Studi Ma'ani, Oleh: Rokhmad

\title{
STUDI MA'ANI AL-HADITS (Hadis-Hadis Tentang Laba Perdagangan)
}

\author{
Rokhmad*
}

\begin{abstract}
Abstrak
Salah satu hadis yang perlu dikaji adalah hadis yang secara tekstual membolehkan mengambil laba perdagangan lebih dari seratus persen. Setelah dikaji dengan menggunakan metode Ma'ani al-Hadis $\backslash$, hadis tentang laba perdagangan tidak hanya dipahami secara tekstual, tetapi bisa dipahami secara kontekstual, faktor historis pada saat disabdakannya hadis ini sangat membantu dalam memahami hadis secara benar.

Dengan menggunakan metode Ma'ani al-Hadis $\backslash$ a hadis tentang laba perdagangan tidak hanya bisa dipahami secara tekstual tetapi juga dapat dipahami secara kontekstual. Faktor historis pada saat disabdakan hadis ini, sangat membantu dalam memahami hadis secara benar. b. Islam tidak memberikan batasan tertentu terhadap laba dalam perdagangan. Hal ini diserahkan kepada masing-masing pedagang dan tradisi masyarakat sekitar, dengan tetap memelihara kaidah-kaidah keadilan dan kebijakan serta larangan memberikan mad\}arat terhadap diri sendiri ataupun terhadap orang lain.
\end{abstract}

Kata Kunci : Studi, Ma’ani Al-Hadits

\section{Pendahuluan}

Perdagangan merupakan jalan yang wajar dalam mencari nafkah untuk memenuhi kebutuhan hidup, dan setiap orang pun bebas untuk berusaha mendapatkan harta dan mengembangkannya. Untuk memperoleh laba yang didambakan, ada banyak cara yang dilakukan penjual untuk mempengaruhi konsumen agar membeli barang dagangannya.

\footnotetext{
*Dosen Institut Agama Islam Tribakti Kediri
}

Vol. 22 Nomor. 2 Juli 2011 
Studi Ma'ani, Oleh: Rokhmad

Permasalahan yang timbul adalah bagaimana relevansi hadis tentang laba perdagangan jika dikaitkan dengan konteks kekinian, sehingga para pedagang dapat mengambil laba dalam transaksi perdagangan dan tujuan dari perdagangan itu sendiri dapat terpenuhi.

Hadis merupakan sumber tasyri' kedua setelah al-Qur'an, pengkajian ulang serta pengembangan pemikiran terhadap hadis perlu dilakukan dengan pemaknaan kembali terhadap hadis. Salah satu hadis yang perlu dikaji adalah hadis yang secara tekstual membolehkan mengambil laba perdagangan lebih dari seratus persen. Setelah dikaji dengan menggunakan metode Ma'ani al-Hadis $\backslash$, hadis tentang laba perdagangan tidak hanya dipahami secara tekstual, tetapi bisa dipahami secara kontekstual, faktor historis pada saat disabdakannya hadis ini sangat membantu dalam memahami hadis secara benar.

\section{Pengertian dan Tujuan Perdagangan}

Perdagangan menurut Kamus Besar Bahasa Indonesia Kontemporer adalah persetujuan saling mengikat antara penjual, yakni pihak yang menyerahkan barang, dan pembeli sebagai pihak yang membayar harga yang dijual. ${ }^{1}$

Dalam bahasa Arab, perdagangan disebut al-Bai' (البيع) yang merupakan bentuk masdar dari بياع - بييع - بيعا yang artinya menjual. ${ }^{2}$ Sedangkan kata beli dalam bahasa Arab dikenal dengan شراءع y masdar dari kata شرى - بشزى - شراء artinya membeli. ${ }^{3}$ Namun pada umumnya kata بيع itu sudah mencakup keduanya, kata بيع diartikan dengan مطلق المبادلة yang artinya mutlak tukar menukar.

Di kalangan ulama ada yang mempunyai kesamaan pendapat مقابلة : dalam merumuskan pengertian perdagangan menurut bahasa yaitu شئ بشئ مقئ

${ }^{1}$ Peter Salim dan Yunny Salim, Kamus Besar Bahasa Indonesia Kontemporer (Yogyakarta: Modern English Press, 1991), h. 626.

${ }^{2}$ A.W. Munawir, Kamus al-Munawir: Arab-Indonesia Terlengkap, cet 14 (Surabaya: Pustaka Progresif, 1997), h. 124.

${ }^{3}$ Ibid., h. 716.

${ }^{4}$ Al-Sayyid Sābiq, Fiqh al-Sunnah (Qahirah: Dār al-Fath \} Lili'lāmi al-'Arabi, 1990), III: 198.

${ }^{5}$ Muhammad Syarbini, al-Iqna' (Bandung: Syirkatu al-Ma'ārif, t.t.), II: 2 
Zainuddin. ${ }^{6}$ Jadi kesimpulannya perdagangan menurut bahasa ialah mengganti atau menukar sesuatu dengan sesuatu.

Sedangkan pengertian perdagangan menurut istilah, para ulama berbeda pendapat. Al-Sayyid Sābiq mengemukakan bahwa perdagangan menurut istilah ialah:

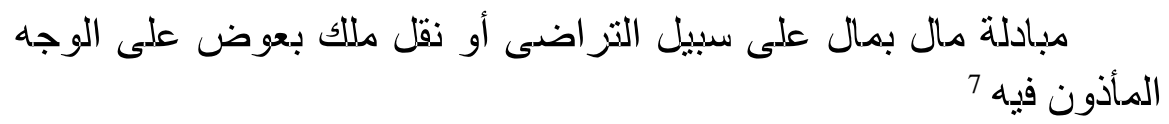

Artinya: Tukar menukar harta dengan harta yang dilakukan berdasarkan kerelaan atau memindahkan hak milik dengan (mendapatkan benda lain) sebagai ganti dengan jalan yang diizinkan oleh syara'.

Hasbi al-Shiddieqy mengatakan bahwa jual (menjual sesuatu) adalah memilikkan pada seseorang sesuatu barang dengan menerima dari padanya harta (harga) atas dasar kerelaan dari pihak penjual dan pihak pembeli. ${ }^{8}$ Dari beberapa defenisi di atas, Abdul Mujib merumuskan defenisi "al-bai" sebagai pelaksanaan akad untuk penyerahan kepemilikan suatu barang dengan harta atau atas saling rid \}a>, atau ijab đan qabul atas dua jenis harta yang tidak berarti bederma, atau menukarkan harta dengan harta bukan atas dasar tabarru'.9

Dengan memahami beberapa arti di atas, maka dapat disimpulkan bahwa perdagangan itu dapat terjadi dengan cara:

1. Pertukaran harta antara dua pihak atas dasar saling rela.

2. Memindahkan milik dengan ganti yang dapat dibenarkan yaitu berupa alat tukar yang sah dalam lalu lintas perdagangan. ${ }^{10}$

Dalam cara pertama, yaitu pertukaran harta atas dasar saling rela itu dapat dikatakan perdagangan dalam bentuk barter (dalam pasar tradisional), sedangkan dalam cara yang kedua, berarti barang tersebut dipertukarkan dengan alat ganti yang dapat dibenarkan. Adapun yang

${ }^{6}$ Syekh Zainuddin bin Abdul Aziz, Fath al-Mu'in (Mesir: Dar al-Kutub al'Arabi, t.t.), h. 66.

${ }^{7}$ Al-Sayyid Sabiq, Fiqh al-Sunnah, h.198

${ }^{8}$ Hasbi al-Siddieqy, Hukum-hukum Fiqh Islam (Semarang: Pustaka Rizki Putera,1997), h. 336.

${ }^{9}$ M. Abdul Mujib dkk, Kamus Istilah Fiqh, cet 2 (Jakarta: Pustaka Firdaus, 1994), h. 34.

${ }^{10}$ Chairuman Pasaribu dan Sahrawardi K. Lubis, Hukum Perjanjian dalam Islam (Jakarta: Sinar Grafika, 1994), h. 33

Vol. 22 Nomor. 2 Juli 2011 
Studi Ma'ani, Oleh: Rokhmad

dimaksud dengan ganti rugi yang dapat dibenarkan berarti milik atau harta tersebut diperuntukkan dengan alat pembayaran yang sah dan diakui keberadaannya, misalnya uang rupiah dan lain sebagainya. ${ }^{11}$

Dengan melaksanakan transaksi perdagangan ini, manusia mempunyai tujuan yaitu untuk kelangsungan hidup manusia yang teratur dengan saling membantu antara sesamanya di dalam hidup bermasyarakat, dimana pihak penjual mencari rizki dan laba, sedangkan pembeli mencari alat untuk memenuhi kebutuhan hidupnya.

Sebagai umat beragama, tujuan yang terpenting dalam perdagangan adalah untuk mendapatkan rid $\} \bar{a}$ Allah agar perdagangan tersebut menjadi berkah dan berhasil. Untuk itu hendaklah setiap pedagang (pengusaha) muslim dan pembeli dapat menerapkan syari'at Islam dalam segala usahanya.

\section{Prinsip dan Dasar Ekonomi Islam}

Islam sebagai agama universal tidak hanya berisi ajaran mengenai hubungan manusia dengan Tuhannya yang berupa ibadah, tetapi juga mengatur hubungan manusia dengan manusia yang disebut muamalah. Muamalah merupakan kegiatan manusia dalam perannya sebagai khalifah di muka bumi, yang bertugas menghidupkan dan memakmurkan bumi dengan cara interaksi antar umat manusia, misalnya melalui kegiatan ekonomi.

Kegiatan ekonomi adalah kegiatan dalam upaya memudahkan manusia memenuhi kebutuhan hidupnya. Untuk memenuhi kebutuhan tersebut, manusia senantiasa bertarung dengan kekuatan-kekuatan alam untuk mengeluarkan daripadanya makanan, minuman, pakaian dan tempat tinggal. Karena adanya berbagai macam kebutuhan, situasi dan lingkungan hidup yang berbea-beda, maka terjadilah antara sesama warga masyarakat berbagai macam perhubungan (mu'amalah).

Untuk menjamin keselamatan, kemakmuran dan kesejahteraan hidup di dunia maupun di akhirat, Islam telah mengatur banyak tentang muamalah tersebut dalam sebuah sistem ekonominya, yang terkenal dengan sistem ekonomi Islam.

Ekonomi Islam adalah suatu sistem ekonomi yang berlandaskan kepada al-Qur'an dan al-hadis, yang menekankan kepada nilai-nilai

\footnotetext{
${ }^{11} I b i d .$, h. 34.
} 
keadilan dan keseimbangan. Dengan demikian, Islam adalah agama yang memandang betapa pentingnya keadilan demi terciptanya masyarakat yang adil, makmur dan sejahtera. Hal ini tercermin dari perhatiannya yang besar kepada kaum yang lemah, yaitu menjamin dan melindungi kehidupan mereka tanpa menganiaya mereka seperti yang dilakukan oleh kaum kapitalisUntuk mencapai hal tersebut, Islam telah memberikan konsep-konsep tentang prinsip-prinsip ekonomi Islam, yaitu:

1. Kebebasan individu

2. Hak terhadap harta

3. Ketidaksamaan ekonomi dalam batasan

4. Kesamaan sosial

5. Keselamatan sosial

6. Larangan menumpuk kekayaan

7. Larangan terhadap institusi anti-sosial

8. Kebajikan individu dalam masyarakat. ${ }^{12}$

Salah satu nilai dasar pada sistem ekonomi Islam adalah keadilan antar sesama manusia. Ini menunjukkan bahwa masalah keadilan berkaitan secara timbal balik dengan kegiatan bisnis, khususnya bisnis yang baik dan etis. Di satu pihak terwujudnya keadilan dalam masyarakat akan melahirkan kondisi yang baik dan kondusif bagi kelangsungan bisnis yang baik dan sehat. Tidak hanya dalam pengertian bahwa terwujudnya keadilan akan menciptakan stabilitas sosial yang menunjang kegiatan bisnis, melainkan juga dalam pengertian sejauh prinsip keadilan dijalankan akan lahir wajah bisnis yang baik dan etis. Di lain pihak, praktek bisnis yang baik, etis, adil, dan fair akan ikut mewujudkan keadilan dalam masyarakat. Sebaliknya, jika ketidak adilan yang merajalela akan menimbulkan gejolak sosial yang meresahkan para pelaku bisnis.

Islam memiliki suatu konsep masyarakat yang berkeadilan. Kata kunci yang digunakan al-Qur'an dalam masalah ini adalah adl dan ihsan di satu sisi dan istikbar di sisi lain. Masyarakat Islam yang ideal harus didasarkan pada keadilan dan nilai-nilai kebaikan serta tiadanya eksploitator yang angkuh, yang disebut istikbar, karena mengeksploitasi mustad'afin. Keadilan dan eksploitasi tidak dapat menjadi satu.

\footnotetext{
${ }^{12}$ Budiono, Ekonomi Mikro (Jogjakarta: BPFE-UGM, t.th), h. 2.
} 
Studi Ma'ani, Oleh: Rokhmad

Perkembangan kapitalisme didasarkan pada eksploitasi dan akumulasi modal, sedangkan al-Qur'an mengajarkan praktek dagang yang jujur dan mencari laba dengan cara yang adil (bukan mencari laba secara berlebih-lebihan, profiteering). ${ }^{13}$ Keadilan dan kebijakan merupakan prinsip pokok ekonomi Islam agar tercapai dua sasaran, yaitu:

1. Kekayaan tidak dipusatkan pada sebagian kecil tangan manusia, namun melalui situasi yang kontinyu pada komunitas.

2. Berbagai ragam rakyat yang berpartisipasi dalam bidak kekayaan nasional mendapatkan imbalan secara adil dan pantas. ${ }^{14}$

Dari beberapa konsep di atas, dapatlah disimpulkan bahwa Islam menghendaki agar sumber-sumber kekayaan tidak tertumpuk pada satu tempat secara besar-besaran, tetapi beredar dan berpindah-pindah di antara individu hingga masing-masing memperoleh bagian kekayaan yang sah dan layak.

Termasuk dari ciri-ciri Islam adalah bahwa Islam telah mengakui manusia sebagai makhluk yang memiliki fitrah dan instinginsting sosial, khususnya kecintaan terhadap harta benda. Namun harus diketahui juga bahwa ekonomi Islam merupakan bagian dari sistem Islam. Maka ekonomi Islam tidak bisa terlepas dari aqidah dan syari'at Islam, bahkan mempunyai hubungan yang sempurna. Dengan demikian pada dasarnya kegiatan-kegiatan ekonomi dalam Islam bersifat pengabdian, dan merupakan cita-cita luhur yang semata-mata tidak untuk merealisir laba materiil saja. Kebebasan ekonomi Islam bukanlah merupakan kebebasan yang mutlaq atau tanpa batas, akan tetapi terikat oleh norma-norma yang digariskan dalam Islam, yaitu ikatan keadilan demi terwujudnya kemaslahatan umum. Oleh karena itu, jika tujuan ekonomi tidak semata-mata untuk merealisir laba materiil yang sudah melekat pada pelaku ekonomi, maka persaingan, egoisme, dan monopoli akan berubah menjadi saling pengertian dan saling tolongmenolong demi kemaslahatan seluruh umat manusia. ${ }^{15}$ Sehingga tujuan

${ }^{13}$ Asghar Ali Engineer, Islam dan Teologi Pembebasan, alih bahasa Agung Prihantoro (Yogyakarta: Pustaka Pelajar, 1999), h. 127.

${ }^{14}$ Afzalurrahmān, Al-Qur'an dalam Berbagai Disiplin Ilmu (Jakarta: LP3ES, 1998), h. 30.

${ }^{15}$ Ahmad Muhammad al-'Assal dan Fathi Ahmad Abd al-Karim, Sistem Ekonomi Islam, Prinsip-prinsip dan Tujuannya, alih bahasa H. Ahmadi dan Anshori Umar Sitanggal (Surabaya: P.T. Bina Ilmu, 1980), h. 20-22. 
dari sistem ekonomi Islam tidak lain adalah untuk kemaslahatan umat manusia secara menyeluruh dapat terwujud.

Dari gambaran tersebut terlihat bahwa sistem ekonomi Islam merupakan sistem yang berwatak sosial tanpa meniadakan hak-hak asasi yang menjadi fitrah manusia.

\section{Kajian Ma'ani Al-H\}Adiś}

\section{Hadis-hadis tentang Laba Perdagangan}

Langkah awal yang dilakukan dalam kajian ma'ani al-h\}adis $\backslash$, adalah mengemukakan hasil takhrij pada setiap hadis yang dijadikan objek kajian sebagaimana terdapat dalam sumber data primer.

Setelah diupayakan takhrij terhadap hadis yang dimaksud dalam kitab sumber primer (al-Kutub al-Tis'ah) dengan menggunakan kitab al-Mu'jam al-Mufakhras li Alfaz al-H\}adis al-Nabawi, dengan

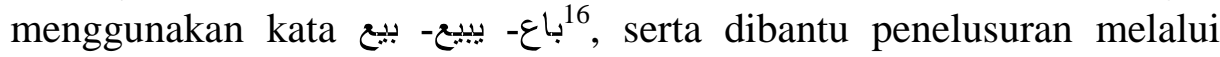
Islamic software CD Mausu'at al-Hadis al-Syarif, maka ditemukan bahwa hadis dimaksud terdapat dalam beberapa kitab hadis.

Berdasarkan hasil penelusuran penulis, hadis tentang laba perdagangan terdapat dalam beberapa kitab yaitu Sahih Bukhari sebanyak 1 buah, Sunan Ibn Majah sebanyak 1 buah, Sunan Abu Dawud sebanyak 1 buah, Sunan al-Tirmizi sebanyak 1 buah, dan Musnad Ah Jmad Ibn H Janbal sebanyak 2 buah. Sehingga hadis-hadis tentang laba perdagangan dalam Kutub al-Tis'ah sebanyak 5 buah.

Dari semua kitab hadis tersebut sahabat yang meriwayatkan hadis tentang laba perdagangan adalah 'Urwah.

Adapun teks-teks hadis tersebut adalah sebagai berikut:

1. Hadis dalam Sahih al-Bukhari

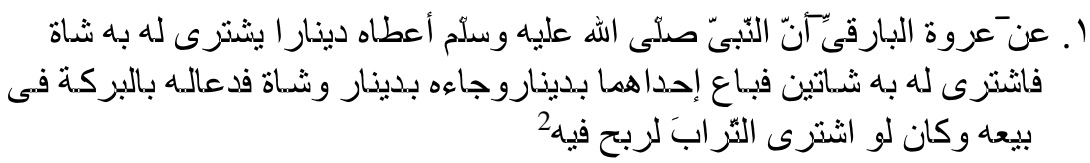

Artinya: Dari 'Urwah al-Bariqi”'Bahwasannya Nabi saw. memberinya uang satu dinar untuk dibelikan kambing. Maka dibelikannya dua ekor kambing dengan uang satu dinar tersebut, kemudian dijualnya yang seekor

\footnotetext{
${ }^{16}$ AJ. Wensinck, Al-Mu'jam al-Mufakhras li Alfaz al-Hadis al-Nabawi, terj. Muhammad Fuad Abd al-Baqi', Juz III (Laeiden: E.J. Brill, 1937), h. 119.

${ }^{17} \mathrm{Abi}$ Abdillah Muhammad ibn Ismail ibn Ibrahim ibn al-Mugirah ibn Bardizbah al-Bukhari al-Ja'fiyyi, Sahih Bukhari, Juz IV (Beirut: Dār al-Fikr, 1401 H/ 1981 M), h. 187.
} 
Studi Ma'ani, Oleh: Rokhmad

dengan harga satu dinar. Setelah itu ia datang kepada Nabi saw. dengan membawa satu dinar dan seekor kambing. Kemudian beliau mendo'akan semoga perdagangannya mendapat berkah. Dan seandainya uang itu dibelikan tanah, niscaya mendapat laba pula"

2. Hadis dalam Sunan at-Tirmizi

$$
\begin{aligned}
& \text { ا ـ حدّثنا أحمد بن سعيد الدّارمىّ حدّثنا حبّان حدّثنا هـارون بن موسدى حدّثنا الزبّيز }
\end{aligned}
$$

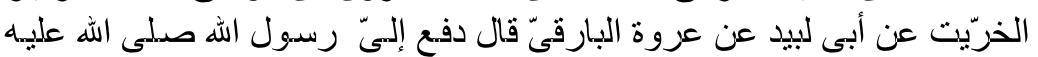

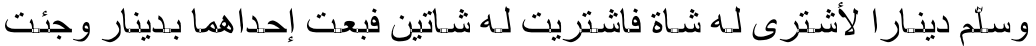

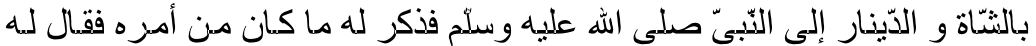

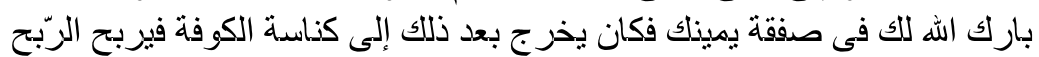

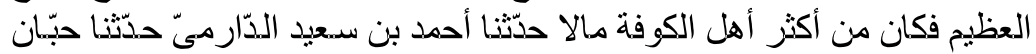

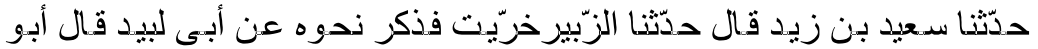

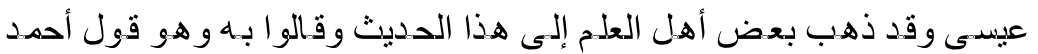

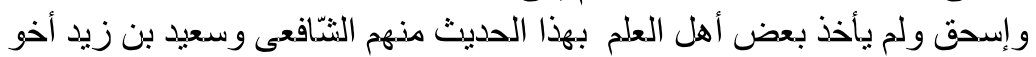

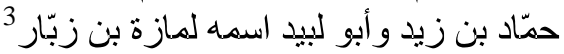

Artinya: Telah menceritakan Ahmad bin Sa'id al-Darimi kepa $\bar{d} a$ kami, telah menceritakan Habban kepada kami, telah menceritakan Harun bin Musa kepada kami, telah menceritakan Zubair bin Khirit kepada kami dari Abu Labid dari Urwah al-Bariqi berkata: Rasulullah saw. menyerahkan kepadaku uang satu dinar untuk dibelikan seekor kambing. Maka saya membelikan untuknya dua ekor kambing dan saya menjualnya lagi yang seekor dengan harga satu dinar. Saya datang kepada Nabi saw. dengan membawa seekor kambing dan laba satu dinar dan saya sebutkan kejadiannya kepada beliau. Maka sabda Nabi:" Semoga Allah memberi keberkahan kepadamu di dalam perdaganganmu." Sesudah peristiwa itu Urwah al-Bāriqi pergi ke kota Kurasan yang ada di Kufah untuk berdagang dan mendapatkan laba yang banyak dan dialah orang yang terkaya di Kufah. Ahmad bin Sa'id menceritakan kepada kami, Habban menceritakan kepada kami, Sa'id bin Zaid menceritakan kepada kami, Zubair bin Khirit menceritakan kēpada kami dari Abu Labid dan mēnyebutkan hādis ini seperti đ̈i atas.

- Sebagian ulama sependapat dengan hadis ini dan mereka mengatakan dengan hadis ini. Inilah pendapat Ah\}mad dan Ishaq. Sebagian ulama yang lain tidak mau menggunakan hadis ini, diantaranya Syafi'i, Sa'id bin saudara Hammad bin Zaid dan Abu Labid yang nama aslinya Lizamah bin Zabbar.

\section{Hadis dalam Sunan Abu Daud}

${ }^{18}$ Imam al-Hafiz Abi 'Isa Muhammad bin 'Isa bin Suran al-Tirmizi, Sunan alTirmizi, Juz II (Beirut: Dar al-Fikr, 1983 M), h. 365. 


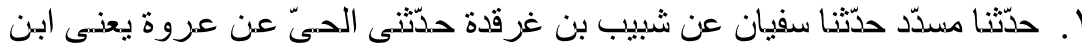

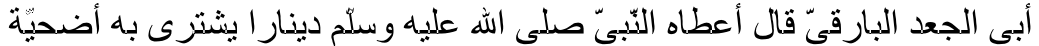

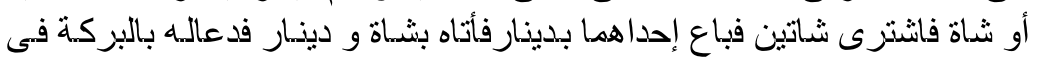

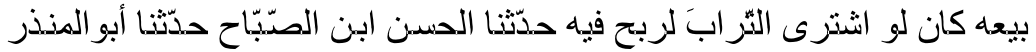

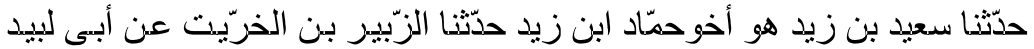

$$
\begin{aligned}
& \text { حدّثنى عزوة البارقى بهذا الخبز ولفظ سونه مختلف } 4
\end{aligned}
$$

Artinya: Telah menceritakan Musaddad kepada kami, telah menceritakan Sufyan kepada kami dari Syabib bin Garqadah, segolongan manusia menceritakan kepada saya dari Urwah bahwasannya Ibn Abi al-Ja'ād al-Bariqi berkata:" Bahwasannya Nabi saw. memberinya uang satu dinar untuk dibelikan kambing. Maka dibelikannya dua ekor kambing dengan uang satu dinar tersebut, kemudian dijualnya yang seekor dengan harga satu dinar. Setelah itu ia datang kepada Nabi saw. dengan membawa satu dinar dan seekor kambing. Kemudian beliau mendo'akan semoga perdagangannya mendapat berkah. Dan seandainya uang itu dibelikan tanah, niscaya mendapat laba pula." telah menceritakan al-Hasān Ibn al-Sabah kepada kami, telah menceritakan Abu al-Munziir kepada kami, telah menceritakan Sai'id bin Zaid saudara Hammad Ibn Zaid, Zubair bin al-Khirit kepada kami dari Abi Labid, Urwah al-Bāriqi menceritakan kepada saya dengan hadis ini dan lafaznya dipertentangkan.

4. Hadis dalam Sunan Ibn Mājah_-

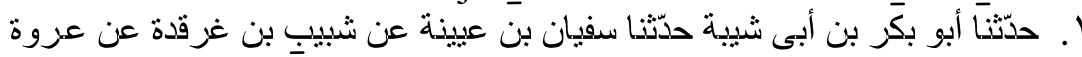

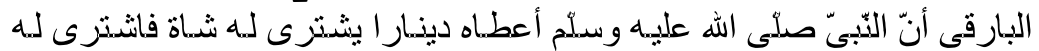

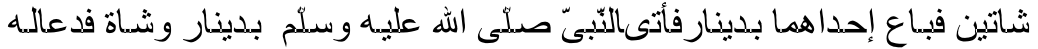

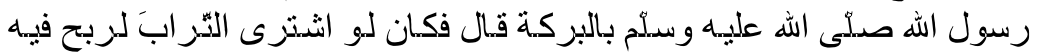

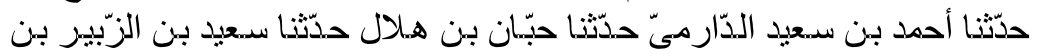

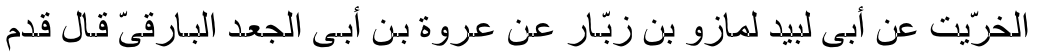

$$
\begin{aligned}
& \text { جلب فأعطانى التّبى صدّى الله عليه وسلّم دينار ا فذكر نحوه }
\end{aligned}
$$

Artinya: Telah menceritakan Abu Bakr bin Abi Syaibah kepada kami, telah menceritakan Sufyan bin Uyainah kepada kami dari Syabib bin Garqadah dari Urwah al-Bariqi bahwasannya Nabi saw. memberinya uang satu dinar untuk dibelikan seekor kambing. Maka dibelikannya dua ekor kambing dengan uang satu dinar tersebut, kemudian dijualnya yang seekor dengan harga satu dinar. Setelah itu ia datang kepada Nabi

${ }^{19}$ Imam al-Hafiz al-Musnif al-Mutqin Abi Daud Sulaiman Ibn al-'As'ad alSajsatani al-Azali, Sunan Abu Daud, Juz III (Beirut: Dar al-Fikr, t.th), h. 265.

${ }^{20}$ Ibn Majah, Sunan Ibn Majah, terj, H. Abdullah Shonhaji dkk, Juz V (Semarang: Asy-Syifa, 1992), h. 385.

$$
=
$$

Vol. 22 Nomor. 2 Juti 2011 
Studi Ma'ani, Oleh: Rokhmad

saw. dengan membawa satu dinar dan seekor kambing. Kemudian beliau mendo'akan semoga perdagangannya mendapat berkah. Dan seandainya uang itu dibelikan tanah, niscaya mendapat laba pula."Telah menceritakan Ahmad bin Sa'id al-Darimi kepada kami, telah menceritakan Habbān bin Hilāl kepada kami, telah menceritakan Sa'id bin Zubair bin al-Khirit kepada kami dari Abi Labid Limazah bin Zabbar dari Urwah bin Abi al-Ja'ad al-Bariqi berkata:" Datangkanlah sesuatu itu”. Maka Nabi saw. memberinya uang satu dinar lalu ia pun menyebutkan kepada yang lainnya.

5. Hadis-hadis dalam Sunan Ah \} mad Ibn $\mathrm{H}$ \}anbal

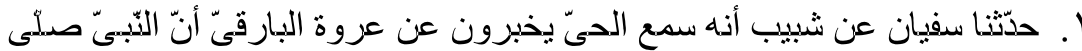

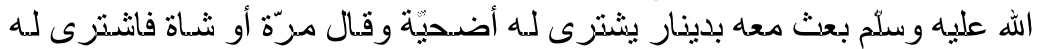

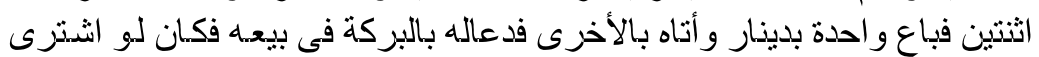

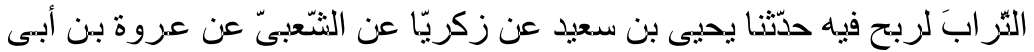

$$
\begin{aligned}
& \text { الجعد قال وحدّثى أبى حدّثنا أبو كامل عن سعيد بن زئ زيد عن الزبّبيز عن أبى لبيد }
\end{aligned}
$$

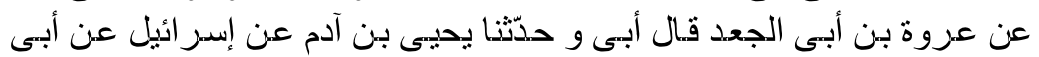

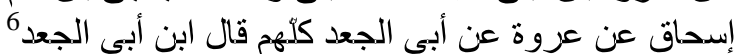

Artinya : Sufyan menceritakan kepada kami dari Syabib bahwasannya ia mendengar dari segolongan manusia yang memberitahukan dari 'Urwah al-Bariqi bahwasannya Nabi saw. memberinya uang satu dinar untuk dibelikan seekor kambing. Dan berkata satu atau seekor kambing. Maka dibelikannya dua ekor kambing dengan uang satu dinar tersebut, kemudian dijualnya yang seekor dengan harga satu dinar. Setelah itu ia datang kepada Nabi saw. dengan seekor kambing. Kemudian beliau mendo'akan semoga perdagangannya mendapat berkah. Dan seandainya uang itu dibelikan tanah, niscaya mendapat laba pula." Yahya bin Sa'id menceritakan kepada kami dari Zakariyyā dari al-Sya'biyyi dari 'Urwah bin Abi al-Ja'ad berkata " Dan Bapak saya mencertakan kepada saya, Abu Kamil menceritakan kepada kami dari Sa'id bin Zaid dari al-Zubair dari Abi Labid dari 'Urwah bin Abi al-Ja'ad bapak saya berkata: Dan Yahya bin Adam menceritakan kepada kami dari Israil dari Abi Ishaq dari Urwah dari Abi al-Ja'ad dan mereka semua mengatakan Ibn Abi al$J a^{\prime} a d$

$$
\begin{aligned}
& \text { Y. حدّثنا أبو كامل حدّثنا سعيد بن زيد حدّثنا الزبّيزبن الخرّيت حدّثنا أبو لبيد عن }
\end{aligned}
$$

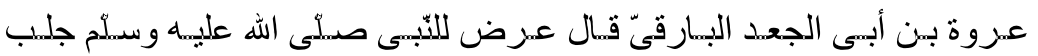

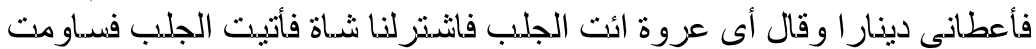

${ }^{21} \mathrm{CD}$ Rom Mausū'ah al-Hadis al-Syarif, Musnad Ahmad ibn Hanbal (Global Islamic Software Conpany: Syirkah al-Baramij al-Islamiyyah al-Dawliyyah, 1991-1997), no. 18549. 


$$
\begin{aligned}
& \text { صاحبه فاشتريت مذه شاتين بدينار فجئت أسبوقهما أو قـال أقودهمـا فلقينـى رجل }
\end{aligned}
$$

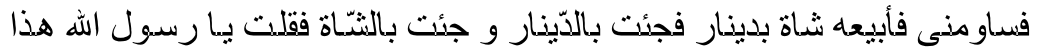

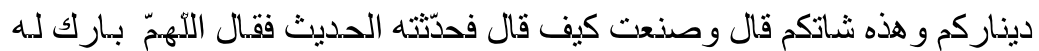

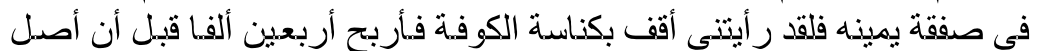

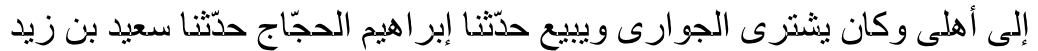

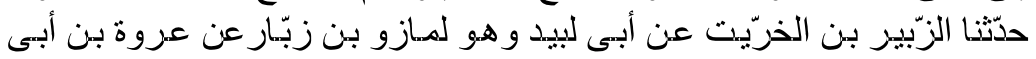

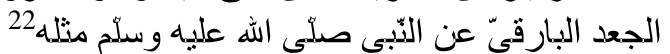

Artinya: Telah menceritakan Abu Kamil kepada kami, telah menceritakan Sa'id bin Zaid kepada kami, telah menceritakan al-Zubair bin al-Khirit kepada kami, telah menceritakan Abu labid kepada kami dari 'Urwah bin Abi al-Ja'ad al-Bariqi berkata bahwasannya ia menginginkan sesuatu untuk Nabi saw maka ia memberiku satu dinar dan ia pun berkata:"Wahai 'Urwah, datangkanlah sesuatu itu." Lalu ia membelikan kami seekor kambing yang diinginkan. Lalu saya pun menawar kepada sahib pemilik kambing itu, maka saya pun membeli dua ekor kambing darinya. Lalu saya pulang dengan menunggangi keduanya atau dikatakan menggiring keduanya, lalu saya bertemu seorang laki-laki dan ia pun menawar kambing itu dan saya pun menjual satu ekor kambing dengan harga satu dinar. Lalu saya pulang dengan satu dinar dan seekor kambing dan saya pun berkata: "Ya Rosulullah, ini dinarmu dan ini kambingmu." Lalu Nabi saw. bertanya:"Bagaimana kejadiannya?". Maka saya pun menceritakan kejadiannya. Maka sabda Nabi:" Ya Allah berilah keberkahan kepadanya di dalam perdagangannya." Sesudah peristiwa itu saya melihatnya pergi ke kota Kurasan yang ada di Kufah dan mendapatkan laba empat puluh ribu sebelum sampai ke tujuannya. Bahwasannya ia membeli dari pedagang dan menjualnya kembali. Telah menceritakan Ibrahim al-Hajjaj kepada kami, telah menceritakan Sa'id bin Zaid kepada kami,telah menceritakan alZubair bin al-Khirit kepada kami dari Abi Labid dan ia Limāzah bin Zabbar dari Urwah bin Abi al-Ja'ad al-Bariqi dari Nabi saw. seperti itu pula.

Dari pemaparan hadis-hadis tentang laba perdagangan, dapat diketahui bahwa hadis tersebut diriwayatkan dari beberapa jalur periwayatan. Setelah mengetahui semua hadis pokok sebagai hasil takhrij diperlukan penelititan akan keasliannya sebelum melakukan pemahaman hadis. Penelitian ini sangatlat penting didasarkan asumsi bahwa pemahaman sahih hanya akan terjadi jika teks yang dipahami benar-benar otentik. Dalam hal ini hadis yang akan dipahami minimal

\footnotetext{
${ }^{22}$ Ibid., no. 18554.
} 
Studi Ma'ani, Oleh: Rokhmad

harus berstatus hasan, dan hadis-hadis di atas semuanya berstatus marfu'.

\section{Kritik Otentisitas Hadis}

\section{a. Kritik Sanad dan Matan}

Selānjutnya untuk mempermudah I'tibar ${ }^{23}$, bahwa tidak ada periwayat yang berstatus Syahid. ${ }^{24}$ Karena sahabat Nabi yang meriwayatkan hadis tersebut hanya 'Urwah bin Ja'ad. Adapun sahabat yang berstatus sebagai muttabi' adalah periwayat tingkat kedua sampai ke empat. ${ }^{25}$ Syabib bin Garqadah mempunyai muttabi' 'Amir bin Syarāhil, 'Amru, Limāzah bin Ziyād. Sufyan bin 'Uyainah mempunyai muttabi' Sufyān bin Sa'id, Zakariyya, Israil, al-Zubair. 'Ali bin Ubaidillah mempunyai muttabi' 'Ubaidillah bin Muhammad, Musa'adah bin Musrahad, Yahya bin Sa'id, Yahya bin Adam, Sa'id bin Zaid, Harun bin Musa. Sedangkan hadis tersebut juga diriwayatkan oleh sejumlah Mukharrij al-Hadis $\backslash$ seperti al-Bukhari, al-Tirmizi, Abu Daud, Ibn Majah, dan Ah\}mad Ibn $\mathrm{H}\}$ anbal.

Yusuf al-Qaradawi dalam kitabnya Fatwa-fatwa Kontemporer memberikan penjelasan tentang tas $\} \mathrm{h}\} \mathrm{ih}\}$ dan tah \}qiqnya Syekh Abdul Azis bin Abdullah yang dikutip dari Kitab Fath\}u al-Bari bahwasanya hadis ini diriwayatkan melalui jalan Syabib bin Garqadah, ia berkata: "Saya mendengar segolongan manusia menceritakan dari Urwah". Dan segolongan manusīa ini, walaupun keadaan mereka tidak diketahui, tidak memungkinkan mereka melakukan kebohongan, sebagaimana yang dikatakan oleh al-Hafizd, dengan menyandarkan datangnya hadis ini dari jalan lain yang merupakan saksi bagi kesahihannya dan diriwayatkan oleh Imam Ah\}mad, Abu Daud, al-Tirmizi, Ibn Mājah dari jalan Sa'id Ibn Zaid dari Zubair al-Khirit dari Labid berkata

${ }^{23}$ I'tibar adalah upaya penyertaan Sanad-sanad dalam meneliti suatu hadis yang pada sanadnya tampak hanya terdapat seorang periwayat saja denganmenyertakan sanad lain akan diketahui adakah periwayat-periwayat lain atau tidak. Lihat Muhammad Tahhan, Tafsir Mustalah) al-Hadis (Surabaya: Syirkah Bungkul Indah, t. th) h. 15. dari kegiatan ini diterapkan ada tidaknya suatu pendukung baik berupa syahid maupun muttabi'.

${ }^{24}$ Syahid adalah seorang sahabat yang meriwayatkan hadis menyerupai sahabat lain baik lafaz-lafz maupun makna. Lihat Muhammad 'Ajjaj al-Khatab, Usul al-Hadis \Ulumuhu wa Mustalahuhu (Beirut: Dār al-Fikr, 1989), h, 366.

${ }^{25}$ Ibid. 
bahwasannya telah menceritakan kepada saya 'Urwah al-Bāriqi dengan pernyataan makna hadis yang sama, juga adanya kesaksian dari Hakim bin Hazām dan telah diriwayatkan oleh Ibn Majah dari Abi Bakr bin Abi Syaibah dari Sufyān dari Syabib dari 'Urwah dengan tidak disebutkan seorangpun diantara keduanya dan riwayat Ali bin Abdullah yakni Ibn al-Madani Syeikh al-Bukhāri yang menunjukkan kesamaan dalam periwayatannya, maka inilah yang dijadikan sandaran bahwasannya hadis ini meskipun pada jalur periwayat al-Bukhāri melalui segolongan orang yang tidak diketahui, tetapi hal itu dikuatkan dengan adanya periwayat dari jalur yang lain yakni al-Tirmizi, Abu Daud, Ibn Majah dan Ah\}mad Ibn Hanbal yang menguatkan kedudukannya, ${ }^{26}$ maka hadis ini dikategorikan sebagai hadis yang marfu' yakni hadis yang periwayatannya sampai kepada Nabi. ${ }^{27}$

Setelah dilakukan penelitian sanad, maka proses berikutnya adalah meneliti kualitas matannya. Adapun langkah-langkah dalam penelitian matan seperti dirumuskan oleh M. Syuhudi Ismā'il adalah:

1. Meneliti matan dengan kualitas sanadnya.

2. Meneliti susunan matan yang semakna.

3. meneliti kandungan matan. ${ }^{28}$

Untuk menetili matan hadis yang diteliti, diperlukan tolak ukur tentang kesahihan matan, sebuah hadis dinilai sahih matannya. Menurut S \}alah al-Din Ibn Ahmad al-Adlabi kriteri kritik matan adalah sebagai berikut:

1. Tidak bertentangan dengan al-Qur'an al-Karim.

2. Tidak bertentangan dengan dengan hadis dan sirah nabawiyyah yang s \}ah \}ih\}.

3. Tidak bertentangan dengan akal, indera atau sejarah.

4. Tidak mirip dengan sabda kenabian. ${ }^{29}$

\footnotetext{
${ }^{26} \mathrm{Ah}$ \}mad ibn Ali bin Hajar al-Asqalani, Fathu al-Bari: Syarh Sahih al-Imam Abu Abdullah ibn Isma'il al-Bukhari, juz II (Beirut: al-Maktabah al-Salafiyah,t.th), h. 635 .

27 CD Rom Mausu'ah al-Hadis al-Syarif (Global Islamic Software Conpany: Syirkah al-Baramij al-Islamiyyah al-Dawliyyah, 1991-1997)

${ }^{28}$ M. Syuhudi Isma'il, Metodologi Penelitian Hadis Nabi (Jakarta: Bulan Bintang, 1992), h. 2002-204..

${ }^{29}$ Salah al-Din Ibn Ah $\}$ mad al-Adlabi, Metodologi Kritik Matan Hadis, alih bahasa. M. Qadirun, Ahmad Musyafiq (Jakarta: Gaya Media Pratama, 2004), h. 209.
}

Vol. 22 Nomor. 2 Juli 2011 
Studi Ma'ani, Oleh: Rokhmad

Ulama hadis barulah menganggap penting penelitian matan untuk dilakukan setelah sanad dan matan itu telah diketahui kualitasnya, dalam hal ini kualitas sahih, atau minimal tidak termasuk berat ked\}a'ifannya.

Kriteria pertama, tidak bertentangan dengan al-Qur'an. Firman Allah yang berkenaan dengan perdagangan sebagai berikut: 30........ Artinya: Padahal Allah menghalalkan perdagangan, dan mengharamkan riba.

$$
\begin{aligned}
& \text { ياأيّها الذين امنوا لاتأكلو أمو الكم بينكم بالباطل إلآ أن تكون تَجارة }
\end{aligned}
$$

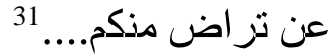

Artinya: Hai orang-orang yang beriman, janganlah kamu saling memakan harta anak yatim dengan jalan yang batil, kecuali dengan jalan perniagaan yang berlaku dengan suka sama suka di antara_kamu....

Ayat-ayat tersebut di atas menjelaskan halalnya perdagangan, kendatipun menurut $a s b \bar{a} b$ al-nuzul ayat-ayat tersebut ditekankan untuk maksud-maksud yang lain yang tidak memberi faedah langsung halalnya perdagangan. Sebab pada ayat pertama menekankan keharaman riba, ayat kedua memberikan tuntunan agar hendaknya perdagangan dilakukan dengan didasarkan atas kerelaan dari kedua belah pihak. Dengan demikian jelaslah bahwa tidak ada suatu pertentangan antara hadis-hadis yang dibahas dengan al-Qur'an alKarim.

Kriteria kedua, pertentangan dengan hadis lain yang lebih kuat kedudukannya. Meskipun ada hadis yang membolehkan pengambilan laba melebihi 100 persen dari modal, tetapi penulis tidak menemukan hadis yang menolak pengambilan laba sebesar 100 persen. Dalam artian bahwasanya hadis-hadis yang dibahas senuanya membolehkan pengambilan laba sebesar 100 persen. Walaupun ada hadis yang membolehkan pengambilan laba lebih dari 100 persen tetapi tidak melarang pengambilan laba sebesar 100 persen.

\footnotetext{
${ }^{30} \mathrm{Al}-\mathrm{Baqarah}(2): 275$.

${ }^{31}$ Al-Nisa' (4): 29.
} 
Studi Ma'ani, Oleh: Rokhmad

Kriteria ketiga, bertentangan dengan akal. Yang dimaksud akal di sini adalah akal yang tercerahkan dengan al-Qur'an dan Hadis yang s\}ah\}ih\}. Secara akal, sistem ekonomi yang berlandaskan kepada alQur'an dan al-hadis, yang menekankan kepada nilai-nilai keadilan dan keseimbangan demi terciptanya masyarakat yang adil, makmur dan sejahtera. Dengan demikian tidak adanya pertentangan hadis yang dibahas dengan akal.

Secara keseluruhan, hadis-hadis tentang laba perdagangan yang diteliti yang diambil dari hadis yang diriwayatkan oleh al-Bukhāri, alTirmizi, Abū Dāud, Ibn Mājah, dan Ah\}mad Ibn H\}anbal, baik sanad maupun matannya adalah s\}ah\}ih\} (s\}ah\}ih\} al-Matan wa s\}ah\}ih\} alIsnād), dengan kata lain, bahwa hadis-hadis tersebut bernilai sebagai hadis s \}ah \}ih\}.

Karena hadis tersebut adalah sahih, maka hadis-hadis tersebut dapat diterima (maqbul), seperti disebutkan Muhammad 'Ajjaj al-Khatib bahwa salah satu syarat suatu hadis dapat dikategorikan sebagai hadis maqbul apabila telah diketahui perawi-perawi yang ada dalam hadis tersebut tidak mengandung cacat/kelemahan (saqim). ${ }^{32}$

\section{b. Pemaknaan Hadis}

\section{Kata-kata Kunci dalam Hadis}

Langkah selanjutnya yang dilakukan dalam memahami matan hadis adalah menjelaskan beberapa kata penting dari segi makna istilahnya. Kata-kata tersebut adalah kata ربح dan بيع , اشترى.

b) اشتثرى

- شرى شراء yaitu bentuk masdar dari kata شترى bentuk masdar dari kata باع - بيبيع - بيعا yang berarti menjual.

c) ربح

ربح yang berarti laba yakni pertumbuhan dalam dagang. ${ }^{35}$ Berkata Azhadi

\footnotetext{
${ }^{32}$ Muhammad 'Ajjaj al-Khatib, Usul al-Hadis' 'Ulumuhu wa Mustalahuhu (Beirut: Dar al-Fikr, 1989), h. 55-56.

${ }^{33}$ A.W. Munawir, Kamus al-Munawir: Arab-Indonesia Terlengkap, cet 14 (Surabaya: Pustaka Progresif, 1997), h. 716.

${ }^{34}$ Ibid., h. 124.

${ }^{35}$ Louwis al-Ma'luf, al-Munjid fi al-Lugah wa al-A'lam, cet ke-28 (Beirut: Dar al-Masyriq, 1986), h. 244
}

Vol. 22 Nomor. 2 Juli 2011 
Studi Ma'ani, Oleh: Rokhmad

maka perdagangan adalah ribh\} (الربح) dan perdagangan (تجارة) yaitu laba atau hasil dagang yang didahului لامنتاع الجواب لامتناع الثّرطلو yang berarti jika, maka pasti ada

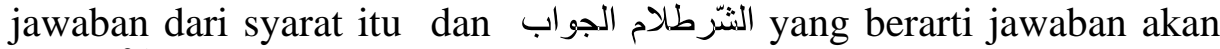
syarat. $^{36}$

Kata ini apabila dikaitkan dengan hadis yang sedang diteliti mengandung pemahaman "jika ingin mendapat laba maka harus melakukan perdagangan”.

\section{Pemahaman Hadis Sesuai dengan Petunjuk Qur'an}

Dalam kaitannya dengan hadis yang sedang dibahas, yaitu hadis tentang laba perdagangan, tidak terdapat satupun ayat al-Qur'an yang secara tersurat menyatakan tentang batasan pengambilan laba perdagangan. Adapun firman Allah yang berkenaan dengan perdagangan sebagai berikut:

$$
37 \text { و أحلّ الله البيع وحرّم الرّبو ا...... }
$$

Artinya: Padahal Allah menghalalkan perdagangan, dan mengharamkan riba.

$$
\text { يأيّها الذين امنوا لاتأكلو أمو الكم بينكم بالباطل إلا أن تكون تجارة عن }
$$

Artinya: Hai orang-orang yang beriman, janganlah kamu saling memakan harta anak yatim dengan jalan yang batil, kecuali dengan jalan perniagaan yang berlaku dengan suka sama suka di antara kamu....

Ayat-ayat tersebut di atas menjelaskan halalnya perdagangan, kendatipun menurut $a s b \bar{a} b$ al-nuzul ayat-ayat tersebut ditekankan untuk maksud-maksud yang lain yang tidak memberi faedah langsung halalnya perdagangan. Sebab pada ayat pertama menekankan keharaman riba, ayat kedua memberikan tuntunan agar hendaknya perdagangan dilakukan dengan didasarkan atas kerelaan dari kedua belah pihak.

${ }^{36}$ Ibid., h. 737.

${ }^{37} \mathrm{Al}$-Baqarah (2): 275.

${ }^{38}$ Al-Nisa' (4): 29. 
Studi Ma'ani, Oleh: Rokhmad

\section{Ada dan Tidaknya Pertentangan dalam Hadis}

Baik dari segi makna maupun lafaz hadis tentang pengambilan laba yang sedang dibahas tidak terdapat adanya suatu pertentangan antara hadis satu dengan lainnya, dikarenakan tidak ditemukannya hadis yang menolak pengambilan laba sebesar 100 persen, hadis-hadis yang dibahas yakni hadis-hadis tentang laba perdagangan baik dari segi makna ataupun redaksi lafaznya tidak terdapat perbedaan. Dalam artian bahwasannya hadis-hadis yang dibahas senuanya membolehkan pengambilan laba sebesar 100 persen. Walaupun ada hadis yang membolehkan pengambilan laba lebih dari 100 persen tetapi tidak melarang pengambilan laba sebesar 100 persen.

\section{4. $\quad$ Latar Belakang Historis Hadis}

Langkah selanjutnya dalam pemahaman matan hadis menurut Yūsuf al-Qarad \}awi adalah pencarian latar belakang (asbāb al-warūd), kondisi dan tujuan penyampaian hadis.

Latar belakang turunnya hadis ini tidak ditemukan, sebagai penguat hadis ini, penulis mencantumkan sebuah riwayat dari Abū Hurairah yang berkaitan dengan hadis larangan mengambil laba dalam perdagangan dengan jalan menipu, yaitu bahwasannya Rasulullah saw. berpapasan dengan seorang penjual makanan, lalu beliau bertanya kepada orang itu, "bagaimana caramu menjual makanan ini?", dan orang itupun menerangkan apa yang ditanyakan Nabi itu. Kemudian Allah mewahyukan kepada beliau: "Masukkan tanganmu dalam makanan itu". Nabi lalu memasukkan tangan beliau, dan ternyata makanan yang ada di bagian bawahnya busuk. Maka beliau pun lalu berkata: "Bukanlah termasuk golongan kami, orang yang menipu kami". Juga riwayat dari Ibn 'Abbas, bahwasannya Rasulullah saw. bertemu dengan seorang penjual makanan di pasar Madinah yang amat menarik perhatian beliau. Lalu beliau memasukkan tangannya ke bahan makanan yang ada di bagian bawah, dan mengeluarkan sesuatu yang tidak sama dengan yang ada di permukaan. Maka beliau pun memarahi penjual makanan itu, dan kemudian berseru: Ayyuha al-nās, tidak dibenarkan menipu dikalangan kaum Muslimin, dan barangsiapa yang menipu kami, ia tidak termasuk golongan kami. Jadi inti dari riwayat ini 
Studi Ma'ani, Oleh: Rokhmad

yaitu dilarangnya mengambil laba dalam perdagangan dengan jalan menipu. ${ }^{39}$

Asbab al-Wurud hadis di atas dapat dipahami bahwasanya larangan mengambil laba yang diperoleh dengan jalan menipu atau menyamarkan perdagangan dengan menyembunyikan cacatnya barang dagangan, atau menampakkannya (mengemasnya) dalam bentuk yang menipu, yang tidak sesuai dengan hakikatnya, dengan tujuan mengecoh pembeli..

\section{Kesimpulan}

Dari uraian di atas, dapatlah penyusun ambil beberapa kesimpulan, yaitu:

1. Dengan menggunakan metode Ma'ani al-Hadits, hadis tentang laba perdagangan tidak hanya bisa dipahami secara tekstual tetapi juga dapat dipahami secara kontekstual. Faktor historis pada saat disabdakan hadis ini, sangat membantu dalam memahami hadis secara benar. Para ulama berbeda pendapat hadis laba perdagangan. Dalam memahami hadis ini mereka ada yang memahami secara tekstual hadis, ada juga yang memahaminya secara kontekstual. Secara tekstual hadis tersebut mengandung makna bahwa Islam tidak membatasi pengambilan laba dalam perdagangan, sedangkan secara kontekstual mengandung makna bahwa pada dasarnya kegiatan-kegiatan ekonomi dalam Islam bersifat pengabdian, dan tidak semata-mata untuk melealisir laba materiil saja. Kebebasan ekonomi Islam bukanlah merupakan kebebasan yang mutlaq atau tanpa batas, akan tetapi terikat oleh norma-norma yang digariskan dalam Islam, yaitu ikatan keadilan demi terwujudnya kemaslahatan umum.

2. Islam tidak memberikan batasan tertentu terhadap laba dalam perdagangan. Yang jelas, hal ini diserahkan kepada masing-masing pedagang dan tradisi masyarakat sekitar, dengan tetap memelihara kaidah-kaidah keadilan dan kebijakan serta larangan memberikan madarat terhadap diri sendiri ataupun terhadap orang lain.

\section{DAFTAR KEPUSTAKAAN}

\footnotetext{
${ }^{39}$ Al-Hafizh Jalaluddin al-Suyuthi, Asbab al-Wurud, alih bahasa. Oleh.
} Taufiqullah, Afif Mohammad (Bandung: Pustaka, 1986), h. 166. 
Studi Ma'ani, Oleh: Rokhmad

Abi Abdillah Muhammad ibn Isma'il ibn Ibrahim ibn al-Mug\}irah ibn Bardizbah al-Bukhari al-Ja'fiyyi, Sahih Bukhari, Juz IV (Beirut: Dar al-Fikr, 1401 H/ $1981 \mathrm{M}$ ),

Afzalurrahmān, Al-Qur'an dalam Berbagai Disiplin Ilmu (Jakarta: LP3ES, 1998),

Ahmad Muhammad al-'Assal dan Fathi Ahmad Abd al-Karim, Sistem Ekonomi Islam, Prinsip-prinsip dan Tujuannya, alih bahasa $\mathrm{H}$. Ahmadi dan Anshori Umar Sitanggal (Surabaya: P.T. Bina Ilmu, 1980),

Ah \}mad ibn Ali bin Hajar al-Asqalāni, Fathłu al-Bari: Syarh Sahih alImam Abū Abdullah ibn Ismā'il al-Bukhari, juz II (Beirut: alMaktabah al-Salafiyah,t.th),

AJ. Wensinck, Al-Mu'jam al-Mufakhras li Alfāz al-H\}adis $\backslash$ al-Nabawi, terj. Muhammad Fuad Abd al-Baqi', Juz III (Laeiden: E.J. Brill, 1937),

Al-Sayyid Sabiq, Fiqh al-Sunnah (Qahirah: Dār al-Fath\} Lili'lami al'Arabi, 1990),

Al-Hafizh Jalaluddin al-Suyuthi, Asbab al-Wurud, alih bahasa. O. Taufiqullah, Afif Mohammad (Bandung: Pustaka, 1986),

Asghar Ali Engineer, Islam dan Teologi Pembebasan, alih bahasa Agung Prihantoro (Yogyakarta: Pustaka Pelajar, 1999),

A.W. Munawir, Kamus al-Munawir: Arab-Indonesia Terlengkap, cet 14 (Surabaya: Pustaka Progresif, 1997),

Budiono, Ekonomi Mikro (Jogjakarta: BPFE-UGM, t.th),

CD Rom Mausū'ah al-Hadis al-Syarif, Musnad Ah\}mad ibn H\}anbal (Global Islamic Software Conpany: Syirkah al-Baramij alIslamiyyah al-Dawliyyah, 1991-1997),

CD Rom Mausu'ah al-Hadis al-Syarif (Global Islamic Software Conpany: Syirkah al-Baramij al-Islamiyyah al-Dawliyyah, 1991-1997)

Chairuman Pasaribu dan Sahrawardi K. Lubis, Hukum Perjanjian dalam Islam (Jakarta: Sinar Grafika, 1994),

Hasbi al-Siddieqy, Hukum-hukum Fiqh Islam (Semarang: Pustaka Rizki Putera, 1997),

Ibn Mājah, Sunan Ibn Majah, terj, H. Abdullah Shonhaji dkk, Juz V (Semarang: Asy-Syifa, 1992),

Imam Taqiyudin, Kifayatu al-Akhyar (Semarang: Toha Putra, t.t.),

Vol. 22 Nomor. 2 Juli 2011 
Imam al-Hafiz Abi 'Isa Muhammad bin 'Isā bin Suran al-Tirmiżi, Sunan al-Tirmiżi, (Beirut: Dar al-Fikr, 1983 M),

Imām al-Hafiz al-Musnif al-Mutqin Abi Daud Sulaiman Ibn al-'As'ad al-Sajsatani al-Azali, Sunan Abu Daud, (Beirut: Dar al-Fikr, t.th),

Louwis al-Ma'luf, al-Munjid fi al-Lug\}ah wa al-A'lam, cet ke-28 (Beirut: Dār al-Masyriq, 1986),

Muhammad Syarbini, al-Iqna' (Bandung: Syirkatu al-Ma'ārif, t.t.),

M. Syuhudi Isma'il, Metodologi Penelitian Hadis Nabi (Jakarta: Bulan Bintang, 1992),

Muhammad 'Ajjāj al-Khatib, Us\}ūl al-H\}adis 'Ulūmuhu wa Must\}alāh\}uhu (Beirut: Dār al-Fikr, 1989),

M. Abdul Mujib dkk, Kamus Istilah Fiqh, cet 2 (Jakarta: Pustaka Firdaus, 1994),

Nasrun Haroen, Fiqh Muamalah, cet. ke-1 (Jakarta: Gaya Media Pramana, 2000),

Peter Salim dan Yunny Salim, Kamus Besar Bahasa Indonesia Kontemporer (Yogyakarta: Modern English Press, 1991),

Syekh Zainuddin bin Abdul Aziz, Fath\} al-Mu'in (Mesir: Dār al-Kutub al-'Arabi, t.t.),

S \}alah al-Din Ibn Ah\}mad al-Adlabi, Metodologi Kritik Matan Hadis, alih bahasa. M. Qadirun, Ahmad Musyafiq (Jakarta: Gaya Media Pratama, 2004), 